\title{
Serum levels of soluble Fas in patients with Graves' ophthalmopathy
}

\author{
Kenji Ohtsuka, Masato Hashimoto
}

\begin{abstract}
Aim-To assess levels of soluble Fas (sFas) in the sera of patients with Graves' ophthalmopathy.

Methods-The subjects in this study were 43 patients with Graves' ophthalmopathy and 11 normal subjects. Serum levels of sFas were determined by sandwich enzyme linked immunosorbent assay. In addition, serum levels of thyroid stimulating antibody (TSAB) were also measured in all the patients.

Results-The mean serum level of sFas was 1.35 (SD 2.03) $\mathrm{ng} / \mathrm{ml}$ in patients with Graves' ophthalmopathy, and $0.93(0.32)$ $\mathbf{n g} / \mathbf{m l}$ in normal subjects. Serum levels of sFas in the subgroup of 24 patients with diplopia (1.98 (2.56) $\mathrm{ng} / \mathrm{ml})$ were significantly higher than those in the subgroup of 19 patients without diplopia $(0.56(0.24)$ $\mathrm{ng} / \mathrm{ml}$ ) and normal subjects $(\mathrm{p}<0.001)$. Serum levels of sFas in the subgroup of 27 patients with extraocular muscle hypertrophy (1.81 (2.46) $\mathrm{ng} / \mathrm{ml})$ were significantly higher than those in the subgroup of 16 patients without extraocular muscle hypertrophy $(0.58(0.26) \mathrm{ng} / \mathrm{ml})$ among the patients with Graves' ophthalmopathy and normal subjects $(p<0.001)$. Serum levels of sFas were not significantly different between the subgroup of 24 patients with proptosis $(1.15(0.98) \mathrm{ng} / \mathrm{ml})$ and the subgroup of 19 patients without proptosis (1.61 (2.88)). In contrast, the serum levels of TSAB in the subgroup of patients with proptosis $(723 \%(1161 \%))$ were significantly higher than those in the subgroup of patients without proptosis $(194 \%$ $(122 \%))(p<0.05)$.
\end{abstract}

Conclusions-Elevated sFas levels were associated with extraocular muscle disorders but not with proptosis. On the other hand, elevated TSAB levels were associated with proptosis but not with extraocular muscle disorders, suggesting different immunological mechanisms for the extraocular muscle disorders and proptosis in Graves' ophthalmopathy. Determination of the serum levels of sFas and TSAB could provide useful markers for evaluation of the immunological processes involved in the development of Graves' ophthalmopathy.

(Br F Ophthalmol 2000;84:103-106)

Graves' ophthalmopathy is a chronic autoimmune disorder affecting the retrobulbar tissues and extraocular muscles, and has strong aetiological links with autoimmune thyroid disease.
However, not all patients with Graves' disease develop severe ophthalmopathy. ${ }^{12}$ Some patients never exhibit symptoms of ophthalmopathy even when autoimmune thyroid disease is observed. The mechanisms for the variations in severity of ophthalmopathy associated with Graves' disease are not known.

Recent studies suggest that retrobulbar fibroblasts are the main target of the immune process in Graves' ophthalmopathy. Histological examination of retrobulbar tissue samples reveals proliferation of fibroblasts accompanied by accumulation of glycosaminoglycans. ${ }^{3}$ Connective tissue, fat, and muscles are infiltrated by mononuclear cells, mainly T cells. ${ }^{4}$ Retrobulbar T cells from patients with Graves' ophthalmopathy specifically recognise autologous retrobulbar fibroblasts. The presence of autoreactive $\mathrm{T}$ cells might be responsible for the induction of ophthalmopathy.

The survival of activated $\mathrm{T}$ cells is regulated by different mechanisms. Apoptosis is one of the primary control mechanisms for the negative selection of an immune response. The interaction between the cell surface molecule Fas and its ligand has been proposed as a primary mechanism initiating $\mathrm{T}$ cell apoptosis. Defects in the Fas/Fas ligand apoptosis pathway have been shown to result in autoimmune disease in humans. ${ }^{6}$ Soluble Fas (sFas) molecule, which lacks the transmembrane domain, because of alternative splicing, inhibits Fas mediated apoptosis of $\mathrm{T}$ cells. ${ }^{7}$ Therefore, elevated serum levels of sFas may be associated with autoimmune diseases, and correlated with the activity of these diseases..$^{8-10}$ Recently, it has been reported that the serum levels of sFas were increased in patients with Graves' disease, and that they were correlated with the free thyroxin levels. ${ }^{11}$ In this study, serum levels of sFas were determined in patients with Graves' ophthalmopathy, and the relation between the serum sFas levels and the severity of ophthalmopathy were investigated.

\section{Patients and methods}

The subjects of our study were 43 consecutive patients (age range 15-74 years; mean 43 years; 33 women, 10 men) with Graves' ophthalmopathy examined at Sapporo Medical University Hospital between May and September 1998, and 11 normal volunteers (age range 23-51 years; mean 36 years; nine women, two men). We confirmed that each normal volunteer has no symptoms of autoimmune diseases up to the present. Informed consent was obtained from all the subjects after the nature of the examination had been explained.

The diagnosis of Graves' disease was based on history; conventional symptoms of thyro-
Accepted for publication 23 August 1999 
toxicosis associated with a diffusely enlarged goitre; elevated levels of serum T3, free T3, $\mathrm{T} 4$, and free $\mathrm{T} 4$; suppression of the serum thyroid stimulating hormone (TSH); and increased thyroidal ${ }^{131}$ I uptake. Elevated antithyroid stimulating antibody (TSAB), antithyroglobulin antibody (TGAB), and antithyroid peroxidase antibody (TPOAB) titres or the presence of ophthalmopathy provided supporting evidence for the diagnosis.

A complete eye examination, including applanation tonometry, exophthalmometry, and measurement of eye movements, were performed by one ophthalmologist at the first visit before any systemic medical treatments in all the patients. Serum samples were stored at $-80^{\circ} \mathrm{C}$ for later determination of sFas levels. Serum levels of TSAB, antithyroglobulin antibody, and antithyroid peroxidase antibody were also measured in all the patients. Coronal and axial computed tomographic scans of the orbit were performed in all 43 patients, and the thickness of the extraocular muscles and proptosis were measured. All patients were classified in three different ways depending on the presence or absence of diplopia, presence or absence of extraocular muscle hypertrophy, and presence or absence of severe proptosis. Diplopia was defined as double vision in any eye positions in the red glass test. Extraocular
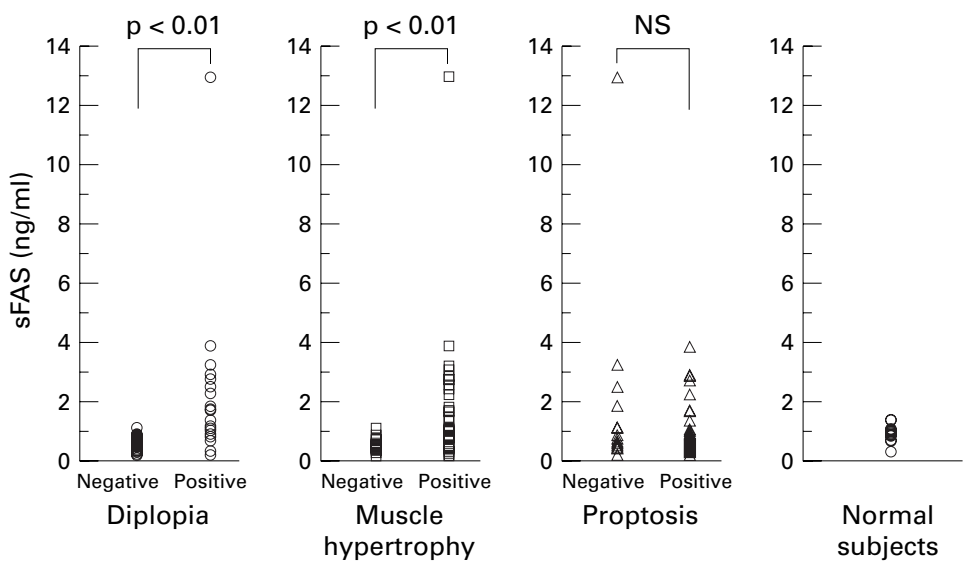

Figure 1 Serum levels of sFas in six subgroups of patients with Graves'ophthalmopathy: diplopia negative and positive, extraocular muscle hypertrophy negative and positive, proptosis negative and positive groups, and normal subjects.
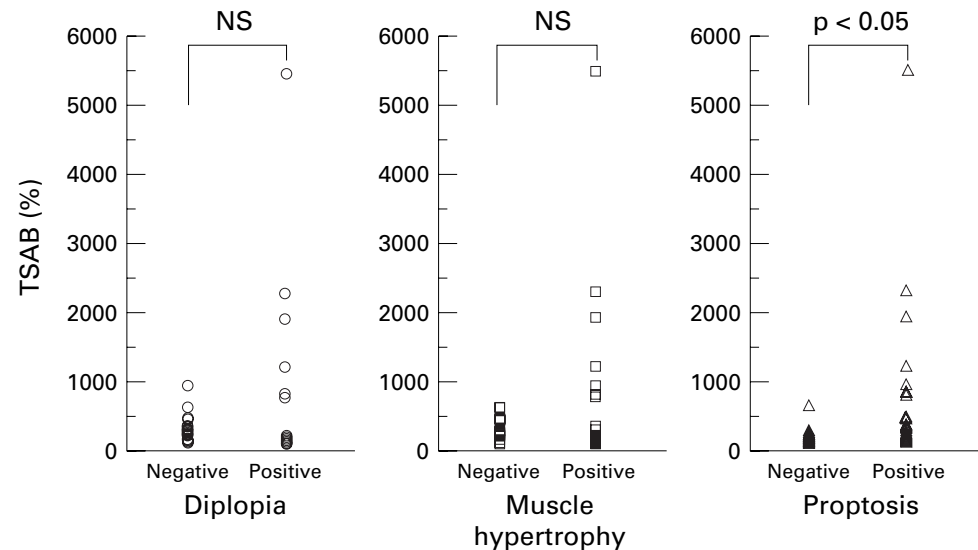

Figure 2 Serum levels of TSAB in six subgroups of patients with Graves' ophthalmopathy: diplopia negative and positive, extraocular muscle hypertrophy negative and positive, and proptosis negative and positive groups. muscle hypertrophy was defined as thickness of any of the rectus muscles more than the diameter of the optic nerve in coronal computed tomographic scans. The criterion for diagnosis of proptosis was defined according to an exophthalmometry result of $=19 \mathrm{~mm}$ or a 3 $\mathrm{mm}$ difference in between the two eyes.

Serum levels of sFas were determined by sandwich enzyme linked immunosorbent assay with a sFas ELISA kit (MBL, Nagoya, Japan). The detection limit was $0.01 \mathrm{ng} / \mathrm{ml}$ with an intra-assay coefficient of variation of $3.9 \%$ and interassay coefficient of variation of $3.8 \%$. Serum samples were tested at a dilution of 1:5. Serum levels of TSAB were determined using porcine thyroid cells. A crude $\gamma$ globulin fraction obtained from sera by the polyethylene glycol precipitation method was used for the assay of TSAB. The serum sample of each patient was tested twice, and the average was used to denote the serum levels of sFas and TSAB in a given patient. The serum levels of sFas and TSAB in the subgroups were compared by the Mann-Whitney U test.

\section{Results}

The mean serum level of sFas was 1.35 (SD 2.03) $\mathrm{ng} / \mathrm{ml}(\mathrm{n}=43)$ in patients with Graves' disease and $0.93(0.32) \mathrm{ng} / \mathrm{ml}(\mathrm{n}=11)$ in normal subjects. The serum levels of $\mathrm{sFas}$ in patients with Graves' disease were not significantly higher than those in normal subjects. However, the serum levels of $\mathrm{sFas}$ in the subgroup of patients with diplopia (1.98 (2.56) $\mathrm{ng} / \mathrm{ml}, \mathrm{n}=24$ ) were significantly higher than those in both the subgroup of patients without diplopia (0.56 (0.24) ng/ml, $\mathrm{n}=19)$ (Fig 1) and in normal subjects $(\mathrm{p}<0.001)$. The serum levels of sFas in the subgroup of patients with extraocular muscle hypertrophy (1.81 (2.46) $\mathrm{ng} / \mathrm{ml}, \mathrm{n}=27$ ) were significantly higher than those in both the subgroup of patients without extraocular muscle hypertrophy $(0.58(0.26)$ $\mathrm{ng} / \mathrm{ml}, \mathrm{n}=16$ ) (Fig 1) and in normal subjects $(\mathrm{p}<0.001)$. On the other hand, the serum levels of sFas in the subgroups of patients with neither diplopia nor extraocular muscle hypertrophy were significantly lower than those in normal subjects $(\mathrm{p}<0.001)$.

The mean exophthalmometry measurement value was $19.21(2.78) \mathrm{mm}$ in the subgroup of patients with proptosis $(\mathrm{n}=24)$ and 14.47 (3.08) $\mathrm{mm}$ in the subgroup of patients without proptosis $(n=19)$. The serum levels of $\mathrm{sFas}$ were not significantly different between patients with proptosis $(1.15(0.98) \mathrm{ng} / \mathrm{ml})$ and patients without proptosis (1.61 (2.88)) (Fig 1).

In contrast, the serum levels of TSAB in patients with proptosis $(723 \%(1161 \%))$ were significantly higher than those in patients without proptosis $(194 \%(122 \%))(p<0.05)$, while they were not significantly different between patients with and without diplopia and between patients with and without extraocular muscle hypertrophy (Fig 2). The serum levels of $\mathrm{sFas}$ were not correlated with the serum titres of TSAB, TGAB, or TPOAB (Fig 3). 

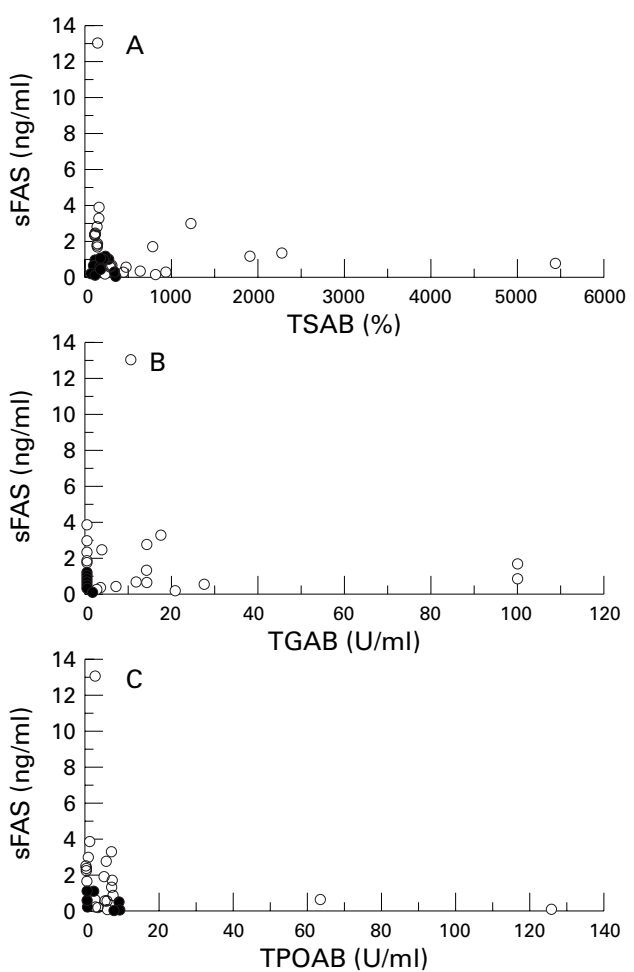

Figure 3 Relations between sFas levels and titres of TSAB (A), TGAB (B), and TPOAB (C).

\section{Discussion}

The serum levels of sFas determined in our study are comparable with the results reported in a previous study of Graves' disease. ${ }^{11}$ The serum levels of sFas were significantly correlated with the severity of diplopia and extraocular muscle hypertrophy, both of which reflect the severity of the extraocular muscle disorders in Graves' disease.

High serum levels of sFas block Fas/Fas ligand mediated apoptosis of $\mathrm{T}$ cells. ${ }^{7}$ Previous studies suggest that autoreactive $\mathrm{T}$ cells are involved in the development of Graves' ophthalmopathy. ${ }^{3-5} \mathrm{~T}$ cells in the retrobulbar tissue from patients with Graves' ophthalmopathy specifically recognise autologous retrobulbar fibroblasts. Cytokines, produced by $\mathrm{T}$ cells as a result of an inflammatory process, can enhance the proliferation of fibroblasts and production of glycosaminoglycan by the fibroblasts. $^{31213}$ This may contribute to the pathogenesis of the extraocular muscle disorders in Graves' disease. ${ }^{14}$ Therefore, it is possible that $\mathrm{sFas}$ is responsible for the induction of extraocular muscle disorders.

The serum levels of sFas in the subgroups of patients with neither diplopia nor extraocular muscle hypertrophy were significantly lower than those in normal subjects. Immunological mechanisms for this are not known. However, it is possible that suppression of serum sFas levels prevents the development of extraocular muscle disorders by facilitating Fas/Fas ligand mediated apoptosis of $\mathrm{T}$ cells.

In contrast, the serum levels of sFas were not associated with the severity of proptosis. However, the serum titres of TSAB were significantly higher in patients with severe proptosis. TSAB is involved in the pathogenesis of autoimmune thyroid disease. ${ }^{15}$ Whether or not TSAB has any role in the development of Graves' ophthalmopathy is not known. Clinically, while no clear correlation has been established between the presence of TSAB and the presence of Graves' ophthalmopathy, it has been reported that severe ophthalmopathy tends to develop in the presence of high titres in the serum TSAB. ${ }^{16}{ }^{17}$ The results in the present study were compatible with the results of these studies. Although the immunological role of TSAB in the development of ophthalmopathy is unknown, TSH receptors exist in retrobulbar tissues, including fibroblasts, and IgGs from patients with Graves' disease stimulate collagen synthesis by fibroblasts. ${ }^{18}{ }^{19}$ It is possible that high serum titres of TSAB are related to the development of exophthalmos.

It is probable that extraocular muscle disorders and proptosis result from different immunological processes. Clinically severely proptotic patients often have minimal extraocular hypertrophy and the converse is also often true, ${ }^{20}$ which provides evidence in support of this hypothesis. In this study also, a discrepancy between the severity of proptosis and extraocular muscle disorders was noted. Five patients showed normal extraocular muscle thickness in coronal computed tomographic scans despite having severe proptosis, and eight patients showed severe extraocular muscle hypertrophy despite having minimal proptosis. In addition, the present study indicates that the serum levels of sFas is correlated with severity of extraocular muscle disorders, while serum TSAB titre is correlated with severity of proptosis. Determination of the serum levels of these two markers could provide useful markers for evaluation of the immunological processes involved in the development of Graves' ophthalmopathy.

1 Bartley GB. The epidemiologic characteristics and clinical course of ophthalmopathy associated with autoimmune thyroid disease in Olmsted County, Minnesota. Trans Am Ophthalmol Soc 1994;92:477-588.

2 Bartley GB, Fatourechi V, Kadrmas EF, et al. Clinical features of Graves' ophthalmopathy in an incidence cohort. Am f Ophthalmol 1996;121284-90.

3 Campbell JC. Immunology of Graves' ophthalmopathy: retrobulbar histology and histochemistry. Acta Endocrinol 1989;121:9-16

4 Weetman AP, Cohen S, Gatter KC, et al. Immunohistochemical analysis of the retrobulbar tissue in Graves' ophthalmopathy. Clin Exp Immunol 1989;75:222-7.

5 Heufelder AE, Bahn RS. Detection and localization of cytokine immunoreactivity in retroocular connective tissue in

6 Drappa J, Vaishnaw AK, Sullivan KE, et al. Fas gene mutations in the Canale-Smith syndrome, an inherited lymphoproliferative disorder associa

7 Cheng J, Zhou T, Liu C, et al. Protection from Fas-mediated apoptosis by a soluble form of the Fas molecule. Science apoptosis by a solub

8 Bijl M, van Lopik T, Limburg PC, et al. Do elevated levels of serum-soluble Fas contribute to the persistence of activated lymphocytes in systemic lupus erythematosus? $\mathcal{f}$ Autoimmun 1998;11:457-63.

9 Inoue A, Koh CS, Sakai T, et al. Detection of the soluble form of the Fas molecule in patients with multiple sclerosis and human T-lymphotropic virus type 1-associated myelopathy. I Neuroimmunol 1997;75:141-6.

10 Nozawa K, Kayagaki N, Tokano Y, et al. Soluble Fas (APO-1, CD95) and soluble Fas ligand in rheumatic diseases. Arthritis Rheum 1997;40:1126-9.

11 Shimaoka Y, Hidaka Y, Okumura M, et al. Serum concentration of soluble Fas in patients with autoimmune thyroid diseases. Thyroid 1998;8:43-7.

12 Heufelder AE, Bahn RS. Modulation of Graves' orbital fibroblast proliferation by cytokines and glucocorticoid receptor agonist. Invest Ophthalmol Vis Sci 1994;35:120-7. 
13 Bahn RS, Heufelder AE. Retroocular fibloblasts: important effector cells in Graves' ophthalmopathy. Thyroid 1992;2 effector

14 Tallstedt L, Norgerg R. Immunohistochemical staining of normal and Graves' extraocular muscle. Invest Ophthalmol Vis Sci 1988;29:175-84.

15 Ludgate ME, Vassart G. The thyrotropin receptor as a model to illustrate receptor and receptor antibody disease. Baillière's Clin Endocrinol Metab 1995;9:95-113.

16 Morris J, Hay ID, Nelson RE, et al. Clinical utility of thyrotropin receptor antibody assays: comparison of radioreceptor and bioassay methods. Mayo Clin Proc 1988;63:707-12.

17 Kazuo K, Fujikado T, Ohmi G, et al. Value of thyroid stimulating antibody in the diagnosis of thyroid associated ophthalmopathy of euthyroid patients. $\mathrm{Br} \mathcal{F}$ Ophthalmol 1997;81:1080-3

18 Bolonkin D, Tate RL, Luber JH, et al Experimental exophthalmos. Binding of thyrotropin and an exophthalmogenic actor derived from thyrotropin to retro-orbital tissue plasma membranes. F Biol Chem 1975;250: 6516-21

19 Rottela CM, Zonefrati R, Toccanfondi R, et al. Ability of monoclonal antibodies to the thyrotropin receptor to increase collagen synthesis in human fibroblasts: an assay which appears to measure exophthalmogenic immunoglobulins in Graves' sera. F Clin Endocrinol Metab 1986; 62:357-67.

20 Nunery WR. Ophthalmic Graves' disease: a dual theory of pathologenesis. Ophthalmol Clin North Am 1991;4:73-87. 